\title{
Risk factors for thoracic and spinal deformities following lung resection in neonates, infants, and children
}

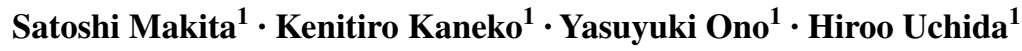

Received: 12 July 2016 / Accepted: 10 October 2016 / Published online: 25 October 2016

(C) The Author(s) 2016. This article is published with open access at Springerlink.com

\begin{abstract}
Purpose We aimed to identify the risk factors for thoracic and spinal deformities following lung resection during childhood and to elucidate whether thoracoscopic surgery reduces the risk of complications after lung resection.

Methods We retrospectively examined the medical records of all pediatric patients who underwent lung resection for congenital lung disease at our institution between 1989 and 2014.

Results Seventy-four patients underwent lung resection during the study period and were followed-up. The median age of the patients at the time of surgery was 5 months (range 1 day-13 years), and 22 were neonates. Thoracotomy and thoracoscopy were performed in 25 and 49 patients, respectively. Thoracic or spinal deformities occurred in 28 of the 74 patients (37\%). Univariate analyses identified thoracotomy, being a neonate (age: $<1$ month) at the time of surgery, and being symptomatic at the time of surgery as risk factors for these deformities. However, a multivariate analysis indicated that only thoracotomy and being a neonate were risk factors for deformities.

Conclusions Thoracoscopic surgery reduced the risk of thoracic and spinal deformities following lung resection in children. We suggest that, where possible, lung resection should be avoided until 2 or 3 months of age.
\end{abstract}

Satoshi Makita

sat-mkt@med.nagoya-u.ac.jp

1 Department of Pediatric Surgery, Nagoya University Graduate School of Medicine, 65 Tsurumai-cho, Showa-ku, Nagoya 466-8560, Japan
Keywords Thoracoscopic surgery · Lung resection · Congenital lung disease $\cdot$ Late complications $\cdot$ Thoracic deformities $\cdot$ Spinal deformities

\section{Introduction}

Previous studies have reported that $18-50 \%$ of pediatric patients that undergo thoracotomy for esophageal atresia or congenital heart disease develop thoracic or spinal deformities [1-8]. However, it remains unclear how frequently deformities occur following thoracotomy for pediatric lung diseases, because only four studies have examined this topic and the reported incidence rates range from 2 to $44 \%$ [9-12]. In recent years, minimally invasive surgery has been applied to more challenging fields, including thoracic surgery for neonates and infants [13]. However, it is unknown whether recent advances in minimally invasive pediatric surgery have helped to prevent such deformities. This study aimed to identify the risk factors for thoracic and spinal deformities following lung resection in neonates, infants, and children, and to elucidate whether thoracoscopic surgery reduces the risk of complications after lung resection.

\section{Patients and methods}

We retrospectively examined the medical records of all pediatric patients who underwent lung resections at our institution between January 1989 and December 2014. The survey was approved by the Ethics Committee of our institution (\#2015-0335). We excluded patients with neoplastic disease. Thoracoscopic lung resection was introduced at our institution in 2008. The procedure was performed via 3 
or 4 ports $(3-5 \mathrm{~mm})$ as previously described [14]. Resected specimens were removed through a $10-\mathrm{mm}$ port at an enlarged initial 5-mm port incision.

Postoperative thoracic and spinal deformities were included as 'musculoskeletal deformity' in the Common Terminology Criteria for Adverse Events version 4.0 and included as 'other (specify)' in the Japan Clinical Oncology Group postoperative complications criteria [15, 16]. Postoperative thoracic and spinal deformities were classified into pectus excavatum, pectus carinatum, scoliosis, and others in this study. Chest wall deformities were diagnosed during visual examinations at our Outpatient Department. Scoliosis was diagnosed as a Cobb angle of $\geq 10^{\circ}$ on radiography according to the definition of early onset scoliosis $[17,18]$. Patients who developed thoracic or spinal deformities prior to surgery were excluded from the postoperative deformity group. The following information was obtained from the patients' medical records as candidate prognostic factors for thoracic and spinal deformities: gender, affected side, type of surgical procedure performed, age at the time of surgery, and whether the patient was symptomatic at the time of surgery.

All of the statistical analyses were performed using the EZR software package (Saitama Medical Center, Jichi Medical University, Saitama, Japan), which is a graphical user interface for the R software program (The R Formulation for Statistical Computing, version 3.0.3) [19]. Univariate analyses were carried out using Fisher's exact test for categorical variables and the Mann-Whitney $U$ test for continuous variables. The variables that exhibited statistical significance in the univariate analyses were included in the multivariate analysis, which was performed using logistic regression. $P$ values of $<0.05$ were considered to indicate statistical significance.

\section{Results}

Eighty patients underwent lung resections during the study period. Since the introduction of thoracoscopic procedures, thoracoscopic resection was attempted in all but one of the patients (an urgent case with severe respiratory distress). The details of six patients were unclear, because they were lost to follow-up. The remaining 74 patients were analyzed. The male-to-female ratio was 1.0:1.1, and the median age of the patients at the time of surgery was 5 months (range 1 day-13 years). There were 22 neonatal patients ( $<30$ days of age). Lung resections were performed for the following diseases: congenital pulmonary airway malformation $(n=51)$, intralobar sequestration $(n=6)$, congenital pulmonary airway malformation in conjunction with intralobar sequestration $(n=6)$, extralobar sequestration $(n=5)$, bronchial atresia $(n=3)$, lobar emphysema $(n=2)$, and a
Table 1 Details of the surgical procedures

\begin{tabular}{llc}
\hline Surgical procedure & $\begin{array}{l}\text { Thoracotomy } \\
(n=25)\end{array}$ & $\begin{array}{l}\text { Thoracoscopy } \\
(n=49)\end{array}$ \\
\hline Right lobectomy & & \\
Upper & 5 & 2 \\
Middle & 0 & 14 \\
Lower & 6 & 1 \\
Bilobectomy & 1 & 0 \\
Total resection & 1 & 2 \\
Partial resection/ & 1 & \\
$\quad$ segmentectomy & & 5 \\
Left lobectomy & & 14 \\
Upper & 7 & 7 \\
Lower & 4 & \\
Partial resection/ & 0 & \\
$\quad$ segmentectomy & & \\
\hline
\end{tabular}

bronchial cyst $(n=1)$. Fifty-two patients underwent thoracoscopic lung resection; three were converted to thoracotomy. Thus, thoracotomy and thoracoscopy were performed in 25 and 49 patients, respectively. The details of the surgical procedures are shown in Table 1. At the time of surgery, 15 patients exhibited symptoms, such as tachypnea and retracted breathing. Thoracotomy was performed significantly more often than thoracoscopy in symptomatic patients. Conversely, the frequencies of these procedures were similar among the neonates (Table 2). The median follow-up period was 8.3 years (range, $2-14$ years) in the thoracotomy group and 4 years (range 1.0-6.8 years) in the thoracoscopy group ( $P=0.000035$, Mann-Whitney $U$ test).

Thoracic or spinal deformities were observed following lung resection in 28 of the 74 patients (37\%) (Table 3). Scoliosis and pectus excavatum were the most common deformities. Among these, one patient with scoliosis was treated with a brace, and three with pectus excavatum underwent surgical correction. Deformities other than scoliosis, pectus excavatum, and pectus carinatum were seen in 4 patients (5.4\%), all of whom exhibited chest asymmetry. Concurrent scoliosis and pectus excavatum occurred in three patients, and concurrent scoliosis and chest asymmetry were seen in one patient. Pectus excavatum occurred significantly earlier than the other deformities $(P=0.0011$, Mann-Whitney $U$ test). Deformities after neonatal surgery included scoliosis $(n=3)$, pectus excavatum $(n=5)$, both scoliosis and pectus excavatum $(n=3)$, chest asymmetry $(n=2)$, and pectus carinatum in $(n=1)$.

Univariate analysis showed that deformities were significantly more common in patients who underwent thoracotomy, patients who underwent lung resection during the neonatal period, and symptomatic patients (Table 4). No significant differences were observed in the extent 
Table 2 Relationships among neonates, symptoms, surgical procedures, and frequency of deformities

\begin{tabular}{lllll}
\hline & $n(\%)$ & Thoracotomy $(n=25)$ & Thoracoscopy $(n=49)^{P \text { value }}$ \\
\hline Neonates that underwent lung resection & 22 & 10 & 12 & $4(33)^{*}$ \\
Frequency of deformities & $14(64)$ & $10(100)^{*}$ & 5 & 0.19 \\
Symptomatic patients that underwent lung resection & 15 & 10 & $1(20)^{* *}$ & $0.0017 *$ \\
Frequency of deformities & $11(73)$ & $10(100)^{* *}$ & 3 & 0.0049 \\
Symptomatic neonates that underwent lung resection & 13 & 10 & $1(33)^{* * *}$ & $0.00047^{* *}$ \\
Frequency of deformities & $11(85)$ & $10(100)^{* * *}$ & $0.039^{* * *}$ \\
\hline
\end{tabular}

* represents incidence rates in neonates that underwent lung resection; ** represents incidence rates in symptomatic patients that underwent lung resection; *** represents incidence rates in symptomatic neonates that underwent lung resection

a Fisher's exact test

Table 3 Deformities that occurred following lung resections

\begin{tabular}{|c|c|c|c|c|c|c|c|c|c|}
\hline \multirow[t]{2}{*}{ Type of deformity } & \multirow[t]{2}{*}{$n$} & \multirow[t]{2}{*}{ (\%) } & \multicolumn{2}{|c|}{$\begin{array}{l}\text { Median onset time fol- } \\
\text { lowing surgery }\end{array}$} & \multicolumn{2}{|c|}{$\begin{array}{l}\text { Thoracotomy } \\
(n=25)\end{array}$} & \multicolumn{2}{|c|}{$\begin{array}{l}\text { Thora- } \\
\text { coscopy } \\
(n=49)\end{array}$} & \multirow[t]{2}{*}{$P$ value $^{\mathrm{a}}$} \\
\hline & & & Months & (Range) & $n$ & $(\%)$ & $n$ & $(\%)$ & \\
\hline Scoliosis & 15 & (20) & 39 & $(13-115)$ & 13 & (52) & 2 & (4) & 0.0000035 \\
\hline Pectus excavatum & 12 & $(16)$ & $7 *$ & $(1-115)$ & 8 & $(32)$ & 4 & (8) & 0.017 \\
\hline Chest asymmetry & 4 & (5) & 35 & $(13-71)$ & 2 & (8) & 2 & (4) & 0.60 \\
\hline Pectus carinatum & 1 & (1) & 48 & (48) & 0 & (0) & 1 & (2) & 1.0 \\
\hline All deformities & 28 & (37) & 23 & $(1-115)$ & 19 & (76) & 9 & (18) & 0.0000022 \\
\hline
\end{tabular}

* $P=0.0011$, Mann-Whitney $U$ test

a Fisher's exact test
Table 4 Prognostic factors (univariate analysis)

\begin{tabular}{lrrr}
\hline Variable & \multicolumn{2}{c}{ Deformity } & $P$ value \\
\cline { 2 - 3 } & $n$ & $(\%)$ & \\
\hline Gender & & & \\
$\mathrm{M}(n=35)$ & 14 & $(40)$ & 0.72 \\
$\mathrm{~F}(n=39)$ & & $(36)$ & \\
Affected side & 13 & $(35)$ & 0.63 \\
$\mathrm{R}(n=37)$ & 15 & $(41)$ & \\
L $(n=37)$ & & & \\
Surgical procedure & 19 & $(76)$ & 0.0000022 \\
Thoracotomy $(n=25)$ & 9 & $(18)$ & \\
Thoracoscopy $(n=49)$ & 26 & $(37)$ & 0.66 \\
Lobectomy or partial resection $(n=71)$ & 2 & $(67)$ & \\
Bilobectomy or total resection $(n=3)$ & & & \\
Age at the time of surgery & & & \\
$<1$ month $(n=22)$ & 14 & $(58)$ & 0.0041 \\
$\geq 1$ month $(n=52)$ & 14 & $(26)$ & \\
$<3$ months $(n=31)$ & 16 & $(52)$ & 0.053 \\
$\geq 3$ months $(n=43)$ & 12 & $(28)$ & \\
Symptomatic at the time of surgery & & & \\
Yes $(n=15)$ & 11 & $(73)$ & 0.0025 \\
No $(n=59)$ & 17 & $(29)$ & \\
\hline
\end{tabular}

of the resection. The relationships among neonatal age ( $<1$ month), being symptomatic at the time of surgery, and/or the type of surgical procedure and the frequency of deformities are shown in Table 2. Thoracoscopic surgery caused nine deformities (Tables 3, 4). Four of these patients had undergone lung resections during the neonatal period, and two had undergone lung resection at 1 month of age. Among the patients that underwent lung resection during the neonatal period, deformities occurred significantly more often after thoracotomy than after thoracoscopy (Table 2).

A multivariate analysis demonstrated that thoracotomy and being a neonate (age: $<1$ month) were independent risk factors for spinal or thoracic deformities following thoracoscopic surgery (Table 5).

\section{Discussion}

This study shows that thoracic and spinal deformities frequently occurred following lung resection during childhood (overall rate: $38 \%$; post-thoracotomy rate: $76 \%$ ) and that thoracotomy and undergoing lung resection during the neonatal period were independent risk factors. This study demonstrates that thoracoscopic surgery reduced the risk of complications after lung resection. 
Table 5 Prognostic factors (multivariate analysis)

\begin{tabular}{lcl}
\hline Prognostic factor & Odds ratio $(95 \% \mathrm{CI})$ & $P$ value \\
\hline Thoracotomy & $14.10(3.84-51.80)$ & 0.000066 \\
Age $<1$ month & $4.44(1.03-19.20)$ & 0.045 \\
Symptomatic & $1.75(0.30-10.20)$ & 0.53 \\
\hline
\end{tabular}

CI confidence interval

During infancy, the skeletal muscles are developing and cutting the latissimus dorsi muscle and/or the serratus anterior muscle during posterolateral thoracotomy can result in postoperative muscular atrophy, which can cause the development of thoracic and/or spinal deformities [2-4, $6,7]$. Axillary thoracotomy or other muscle-sparing thoracotomies might avoid muscular atrophy, but we did not use these procedures. Thoracoscopic lung resection can avoid this and-as shown here-contribute to a reduction in deformities. Similarly, Lawal et al. reported that thoracoscopic surgery significantly reduced the incidence of scoliosis (from 54 to 10\%); however, the study included procedures other than lung resection [8]. Despite the lack of a control group, Albanese and Rothenberg reported that there were no cases of musculoskeletal deformity following 144 thoracoscopic lobectomy procedures during a follow-up period of $1-10$ years [20].

Negative intrapleural pressure is another possible mechanism that may lead to the development of deformities after lung resection. This can be seen in patients with congenital diaphragmatic defects who exhibit pulmonary hypoplasia on the affected side [21]. The negative intrapleural pressure generated by upper airway obstruction in laryngomalacia has also been reported to be related to pectus deformity [22]. In this mechanism, the thorax is deformed because of the negative intrapleural pressure due to the dead space in the thoracic cavity following the resection of space-occupying lesions. The fragile neonatal thorax may be more susceptible to deformities caused by negative intrapleural pressure than the thoraces of older patients. The most dramatic changes in sternum and rib cage morphology occur in childhood when these structures are undergoing ossification [23, 24]. The degree of ossification in neonates, which is the lowest among the developmental stages, may be responsible for the neonatal period being an independent risk factor for thoracic or spinal deformities after lung resection. Based on this result, we have changed our opinion that cystic lesions should be removed during the neonatal period [14]. Thoracoscopic lobectomy for asymptomatic congenital cystic lung disease should be performed later. However, it is important that resection be performed before 6 months of age, because asymptomatic cystic lesions tend to become symptomatic after 6 months, and because inflammation is present even in asymptomatic cases [25-27].
Our patients had an unexpectedly high frequency of thoracic and spinal deformities. One possible reason is that we examined both thoracic and spinal deformities, while the previous studies examined either type of deformity alone. Another reason is that our follow-up period was longer than the follow-up periods reported in the previous studies [9-12]. The majority of deformities, with the exception of pectus excavatum, develop at 3-4 years after surgery; thus, a long follow-up period is required to evaluate the musculoskeletal anomalies that occur following lung resection. Finally, even if mild scoliosis was not diagnosed by a physical examination, the rate at which it was diagnosed on radiography was higher than expected; thus, we consider our findings to be more accurate than those reported in the previous studies.

\section{Compliance with ethical standards}

Conflict of interest The authors declare no conflicts of interest in association with this study.

Open Access This article is distributed under the terms of the Creative Commons Attribution 4.0 International License (http://creativecommons.org/licenses/by/4.0/), which permits unrestricted use, distribution, and reproduction in any medium, provided you give appropriate credit to the original author(s) and the source, provide a link to the Creative Commons license, and indicate if changes were made.

\section{References}

1. Durning RP, Scoles PV, Fox OD. Scoliosis after thoracotomy in tracheoesophageal fistula patients. A follow-up study. J Bone Jt Surg Am. 1980;62:1156-9.

2. Jaureguizar E, Vazquez J, Murcia J, Diez Pardo JA. Morbid musculoskeletal sequelae of thoracotomy for tracheoesophageal fistula. J Pediatr Surg. 1985;20:511-4.

3. Wong-Chung J, France J, Gillespie R. Scoliosis caused by rib fusion after thoracotomy for esophageal atresia. Report of a case and review of the literature. Spine (Phila Pa 1976). 1992;17:851-4.

4. Sistonen SJ, Helenius I, Peltonen J, Sarna S, Rintala RJ, Pakarinen MP. Natural history of spinal anomalies and scoliosis associated with esophageal atresia. Pediatrics. 2009;124:e1198-204. doi:10.1542/peds.2008-3704.

5. Shelton JE, Julian R, Walburgh E, Schneider E. Functional scoliosis as a long-term complication of surgical ligation for patent ductus arteriosus in premature infants. J Pediatr Surg. 1986;21:855-7.

6. Bal S, Elshershari H, Celiker R, Celiker A. Thoracic sequels after thoracotomies in children with congenital cardiac disease. Cardiol Young. 2003;13:264-7.

7. Westfelt JN, Nordwall A. Thoracotomy and scoliosis. Spine (Phila Pa 1976). 1991;16:1124-5.

8. Lawal TA, Gosemann JH, Kuebler JF, Glüer S, Ure BM. Thoracoscopy versus thoracotomy improves midterm musculoskeletal status and cosmesis in infants and children. Ann Thorac Surg. 2009;87:224-8. 
9. Mullassery D, Jones MO. Open resections for congenital lung malformations. J Indian Assoc Pediatr Surg. 2008;13:111-4.

10. Barrena S, Miguel M, Burgos L, Fernández A, Queizán A, Hernández F, et al. Pneumonectomy in children [Article in Spanish]. Cir Pediatr. 2010;23:74-6.

11. Yalcin S, Ciftci A, Karnak I, Ekinci S, Tanyel FC, Şenocak M. Childhood pneumonectomies: two decades' experience of a referral center. Eur J Pediatr Surg. 2013;23:115-20. doi:10.105 5/s-0032-1323159.

12. Vu LT, Farmer DL, Nobuhara KK, Miniati D, Lee H. Thoracoscopic versus open resection for congenital cystic adenomatoid malformations of the lung. J Pediatr Surg. 2008;43:35-9. doi:10.1016/j.jpedsurg.2007.09.012.

13. Fujishiro J, Ishimaru T, Sugiyama M, Arai M, Suzuki K, Kawashima H, Iwanaka T. Minimally invasive surgery for diaphragmatic diseases in neonates and infants. Surg Today. 2016;46:757-63.

14. Kaneko K, Ono Y, Tainaka T, Sumida W, Kawai Y, Ando H. Thoracoscopic lobectomy for congenital cystic lung diseases in neonates and small infants. Pediatr Surg Int. 2010;26:361-5.

15. Cancer Therapy Evaluation Program NCI. Common Terminology Criteria for Adverse Events (CTCAE) Version 4.0. 2009.

16. Katayama H, Kurokawa $\mathrm{Y}$, Nakamura K, Ito H, Kanemitsu Y, Masuda N, Tsubosa Y, Satoh T, Yokomizo A, Fukuda H, Sasako M. Extended Clavien-Dindo classification of surgical complications: Japan Clinical Oncology Group postoperative complications criteria. Surg Today. 2016;46:668-85.

17. Yang S, Andras LM, Redding GJ, Skaggs DL. Early-onset scoliosis: a review of history, current treatment, and future directions. Pediatrics. 2016;. doi:10.1542/peds.2015-0709 (Epub 2015 Dec 7).

18. Cobb J. Outline for the study of scoliosis. Instr Course Lect. 1948;5:261-75.

19. Kanda Y. Investigation of the freely available easy-to-use software 'EZR' for medical statistics. Bone Marrow Transplant. 2013;48:452-8.
20. Albanese CT, Rothenberg SS. Experience with 144 consecutive pediatric thoracoscopic lobectomies. J Laparoendosc Adv Surg Technol A. 2007;17:339-41.

21. Vanamo K, Peltonen J, Rintala R, Lindahl H, Jääskeläinen J, Louhimo I. Chest wall and spinal deformities in adults with congenital diaphragmatic defects. J Pediatr Surg. 1996;31:851-4.

22. Schaerer D, Virbalas J, Willis E, Siegel B, Gonik N, Bent J. Pectus excavatum in children with laryngomalacia. Int $\mathrm{J}$ Pediatr Otorhinolaryngol. 2013;77:1721-3. doi:10.1016/j. ijporl.2013.07.033.

23. Weaver AA, Schoell SL, Stitzel JD. Morphometric analysis of variation in the ribs with age and sex. J Anat. 2014;25:246-61. doi:10.1111/joa.12203.

24. Weaver AA, Schoell SL, Nguyen CM, Lynch SK, Stitzel JD. Morphometric analysis of variation in the sternum with sex and age. J Morphol. 2014;275:1284-99. doi:10.1002/jmor.20302.

25. Stanton M, Njere I, Ade-Ajayi N, Patel S, Davenport M. Systematic review and meta-analysis of the postnatal management of congenital cystic lung lesions. J Pediatr Surg. 2009;44(5):102733. doi:10.1016/j.jpedsurg.2008.10.118.

26. Kotecha S, Barbato A, Bush A, Claus F, Davenport M, Delacourt C, Deprest J, Eber E, Frenckner B, Greenough A, Nicholson AG, Antón-Pacheco JL, Midulla F. Antenatal and postnatal management of congenital cystic adenomatoid malformation. Paediatr Respir Rev. 2012;13(3):162-70. doi:10.1016/j.prrv.2012.01.002 (Epub 2012 Apr 25, quiz 170-1).

27. Conforti A, Aloi I, Trucchi A, Morini F, Nahom A, Inserra A, Bagolan P. Asymptomatic congenital cystic adenomatoid malformation of the lung: is it time to operate? J Thorac Cardiovasc Surg. 2009;138(4):826-30. doi:10.1016/j.jtcvs.2009.01.014 (Epub 2009 Mar 26). 